\title{
Regional Patterns of Forest Transition, Forest Economy and Its Challenge
}

\author{
Bibilari Henry Olufemi, Ph.D \\ Ekiti State Universitiy, Ado Ekiti, Nigeria
}

\begin{abstract}
For millennia before the industrial revolution, forests, woodlands, and trees were the source of land for settlement and cultivation, products and materials for construction, woody biomass for fuel and energy, and indeed, directly for food and nutrition as well. The spread of agricultural revolution depended on the conversion of forests into cultivable land. The continuing contributions of forests to global biodiversity, to the fertility of agricultural lands, and to the welfare of those who depend on them mean that forests are immensely valuable for sustainability. The massive economic contributions forests continue to make to human livelihoods, economic development, and national incomes are the main focus of this report. Changes in forest cover and the economic contributions of forests to development have created many different patterns across the globe. But the basic pattern of deforestation accompanying the initial period of economic growth, followed by a phase during which forest area and cover stabilize and then slowly begin to recover seems to be remarkably consistent - with obvious differences in timing. The specific reasons for this pattern differ - in some cases these reasons are primarily owed to changes in the distribution of economic activities from agriculture to industry to service sectors, in other cases to active government policies aiming to improve forest cover or penalize illegal extraction, and in yet other cases as a result to the role of international capital and trade. But under all these patterns of loss, stabilization, and recovery, the constant is the contributions forests make to international trade, national economies, employment, and household incomes.
\end{abstract}

Key Words: Forest, Transition, Regional Pattern, Deforestation, Agriculture

\section{Introduction}

The dominant economic theme in human-forest relationships over the past two millennia, but especially during the last two centuries, has been one of value abstraction and increasingly intensive management. Humans have depended on forests for a remarkable variety of products, services, and benefits. With rapid economic growth and technological changes, they have refined and added to the values forests make available. Even as deforestation has accompanied early stages of economic growth (Richards and Tucker 1988), advanced levels of economic development are associated with forest transitions and increased forest cover (Grainger 1995). The following review of economic contributions from forests surveys the state of the literature on how forests contribute to human well-being through the many different goods and services they provide, the ways in which they are managed and governed, and some directions for more effective protection of the heritage they constitute and enhancing of the benefits they provide.

Historically, forests have played a major role to influence patterns of economic development, supporting livelihoods, helping structure economic change, and promoting sustainable growth. For millennia before the industrial revolution, forests, woodland, and trees were the source of land for cultivation and settlement, of construction materials, of fuel and energy, and indeed of food and nutrition as well (Williams 2002). The extended use and exploitation of forest resources even before the industrial revolution had led to efforts to conserve forested areas and plant new trees in specific regions of the world. In Europe, France and Germany were leaders in developing policies in the 17th and 18th centuries to regulate the use of and to protect forests. The emergence of forestry as a science with its focus on sustainable timber production was also a hallmark of colonial forest departments founded all over the developing world by European colonizers (Barton 2001). The foundational justification for many forestry departments all over the world was to improve management and enhance the public benefits of forests in terms of soil conservation, watershed protection and flood control. But most forestry departments were also under substantial pressure to generate revenues and often sought to protect forests for commercial exploitation. The consequence was tensions between government forest agencies and the poor populations that depended on forests for their livelihoods (Guha 2000).

Forests continue today to provide the high levels of commercial benefits to households, companies, and governments that formed the initial impetus for protective statutes and policies. The FAO estimates that forest industries contribute more than US\$ 450 billion to national incomes, contributing nearly 1 percent of the global GDP in 2008 and providing formal employment to $0.4 \%$ of the global labor force (FAO 2012). Forests also provide other sources of incomes and subsistence benefits, generate informal work opportunities, and constitute reservoirs of economic values that help ameliorate shocks to household incomes - particularly in rural areas in poor countries (Chomitz and Kumari 1998). But systematically collected data to permit aggregate estimates of nonindustrial economic contributions of forests are simply not available - either at the global or at the national 
level. The individual country level estimates that are available demonstrate that such benefits are substantial, in many cases 3-10 times higher than those for which systematic national and global data are collected.

Hence, this paper estimated the patterns of forest transition, its economy and challenges regionally.

\section{Forest transition in the Brazilian Amazon}

Perez and Skole (2003) examine forest transition theory in emerging secondary forests in the Brazilian Amazon. They use a remote subregion, a frontier sub-region, and a settled sub-region as proxies for points along the forest transition curve. They find that the Amazon region experienced rapid secondary forest expansion without forest depletion. Perez and Skole (2003) explain that the Amazon experienced an income decline that likely hindered agricultural capitalization and shifted land use from crops to pasture and overall resulted in primary forest cover throughout each type of sub-region. They conclude that the Amazon does not exhibit "one long-run forest transition that involves extensive forest depletion before recovery" but rather experiences short, periodic transition cycles, similar to the economic boom-bust cycle of Amazonian development.

Perez and Skole (2003) stress that their findings underscore the importance factors and dynamics that are not well represented in forest transition theory. They propose that forest transition theory can be refined to account for different forest types, recognize different temporal dynamics and focus on local and regional specific biophysical conditions and social drivers as well as external factors that may influence the forest sector.

\section{Multiple trajectories of agriculture and deforestation in the Peruvian Amazon}

Arce-Nazario (2007) illustrates land use change and forest transitions in the Peruvian Amazon as a result of changes in economy, local markets, policy and river dynamics. In 1948, upland agriculture and farm areas expanded into primary forest. As a result of agricultural credit programs that promoted farm crops, farmers left upland farm areas. Consequently, by $196549 \%$ of this upland farm area became secondary forestry. Between 1965 and 1977, the number of agricultural loans increased nine-fold and river migration and extreme flooding occurred throughout the area, resulting in many farmers moving to the city. At this time, the economy was also experiencing an oil boom, which may have resulted in reduced land dependency. After the collapse of the oil boom, farmers again received agricultural support in the 1980s. By 1993, farm density was at its highest level and farmers also deforested swamp areas for charcoal.

When the agricultural credits were discontinued, farming activity reduced. In 2005, the area covered by farms was $10 \%$ less than in 1993. Arce-Nazario (2007) concludes that these findings illustrate the multiple, nonlinear trajectories between agriculture and deforestation, stressing that deforestation trends do not follow a simple or predictable pathway. Arce-Nazario (2007) also notes that afforestation in response to demographic and economic changes is a common pattern in Ecuador, El Salvador and Puerto Rico.

\section{Reforestation in China through government policy}

Song and Zhang (2010) illustrate how forest cover in China increased from 8.6\% in 1949 to $18.2 \%$ in 2003 as a result of central government policies and efforts. They characterize China's forest transition in three stages: 1) unsustainable from 1949 to 1981; 2) recovery from 1982 to 1993; and 3) expansion from 1994 to the present. Between 1949 and 1981, the central government's forest management goals focused on timber extraction to fuel economic reconstruction after WWII. At this time, the government owned $42 \%$ of the total forest area and also set the price for timber. Song and Zhang (2010) characterize this forest resource use as unsustainable because timber volume growth was lower than timber volume harvested.

Between 1982 and 1993 the Chinese government continued to focus on timber production but began to harvest timber primarily from plantation areas to allow natural forest areas to recover. Forest plantations contributed to $80 \%$ of the forest cover increase from 1962-2003. The Chinese government also began several environmental programs focused on protection, such as high afforestation standards, resulting in increases in forest area and timber volume by the end of this stage.

Beginning in 1994, the government no longer focused primarily on forest management and Chinese forest cover expanded. In 1998, the Chinese government adopted a forest policy that prioritized sustainable forest use and environmental protection over timber production. China's economic growth also enabled the government to make forest investments.

In contrast to common assumptions that forest cover may increase following economic development, Song and Zhang (2010) stress, that these forest cover increases are the result of government policy. They note the potential for reforestation gains to be reversed if government policy shifts away from sustainable forest management. 


\section{Reforestation in South Asia}

Nagendra (2010) conducted a meta-analysis of papers from South Asia to examine whether current drivers of reforestation explained forest change pathways (2 in Bangladesh, 6 in India, 14 in Nepal, 1 in Pakistan, 1 in Sri Lanka). She concludes planting and protection primarily drive reforestation and regrowth, often as a result of forest product scarcity, strong conservation ethics and decentralization reforms. While noting that some proponents of the environmental Kuznets curve suggest wealthier countries are more likely to reforest areas as a result of conservation awareness, Nagendra highlights evidence that poor communities also care strongly enough to protect their forests, even when it means they temporarily experience reduced access to forest products.

Figure 1 below summarizes much of the above empirical discussion above by presenting information on forest cover change visually for the different countries in the world in the last five years.
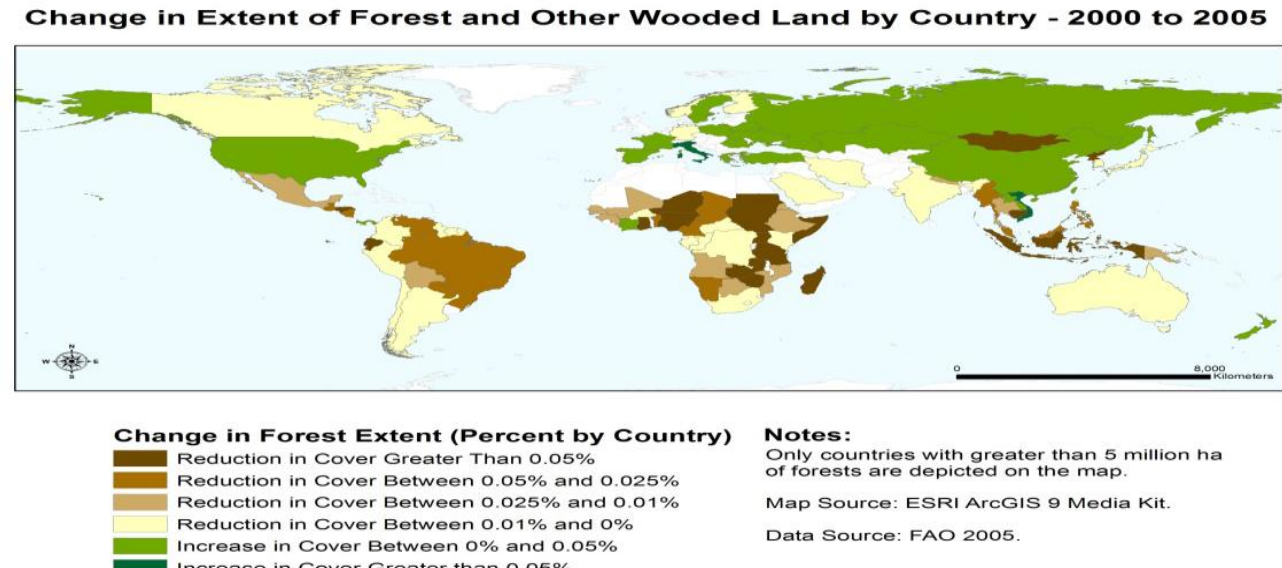

Figure 1: Global forest cover change at the national level (Source: FAO 2006 2011)

\section{Summary of Forest Change Patterns}

The ongoing recovery of forest cover in countries in both the developing and the developed world, under conditions of high and low population density, with rapid and slow growth, and under situations of secure and insecure tenure demonstrates that there is no obvious or necessary relationship between population growth, economic development, and deforestation. This observation is also strengthened by cross-national and temporal variations within countries in the relationship between population, agricultural growth, and deforestation. Indeed, once we begin to look into the specific explanations underpinning the general argument of forest transitions and the drivers of forest loss vs. gain, it becomes clearer that the observed relationships are contingent: Deforestation and afforestation in specific locations have occurred together with a rising global population, demand for forest products, and agricultural output, and are clearly shaped by economic development pathways, levels of technological innovation, and institutional configurations than being the outcome of a trans-historical, immutable association.

\section{Challenges of Forest Economy}

Although many studies on the subject describe the range of benefits forest provide, reliable quantitative data are simply not available for global estimates. Thus, for example, estimates of the numbers of people that rely on forests for some part of their livelihood and income vary between 1 billion and 1.6 billion. But the basis for these estimates is unclear at best. Take another example: many country and subnational studies provide some estimates of benefits from forests to household incomes. A review of 51 studies from 19 countries suggests forest may contribute as much as $22 \%$ of household incomes in these countries (Vedeld 2007). But we do not know if these figures can be extrapolated to other countries. Other analyses have also highlighted the paucity of reliable estimates of the value of forest ecosystem services including their contributions to direct household incomes (Ferraro et al. 2012).

Two distinct, related challenges confront efforts to identify and assess the role and impacts of the economic contribution of forests. First, how we conceive of forests themselves, from "natural" to "forest plantation" to "agricultural crops" that grow trees for non-timber purposes, such as palm oil plantations, will affect and shape the data that is produced. And even once we have decided on an appropriate definition of what constitutes forests, we need to decide what types of incomes, economic uses, employment, and other contributions to include: from logging in the forest, to manufacturing of some type, to transportation along supply chains, to retail jobs created by selling timber to final consumers to domestic economic use. And even 
more complicated are the "indirect" or "multiplier" effects that the forest sector has on employment in other sectors owing to the economic development and growth that result from forest employment and returns on investment. That is, employees and business spend money that creates growth in a range of sectors from consumer goods such as automobiles and computers, to demands on real estate, which themselves provide complex feedback loops. Likewise growth in forest sector employment and business revenue leads to higher tax revenue, which then can permit governments at local, regional and national scales to invest in education, health care, and other social services. Second, identifying the direct and indirect causal impacts of the forest sector on economic life would require some significant expenditure of resources and analytical effort. There are certainly data challenges as also challenges with identifying contributions to the informal sector. However, these challenges have been addressed by many country level researchers and a systematic effort promises to yield important dividends. As figure 5 shows, many countries use wood for fuel, and much of this fuel use is currently neither tracked nor entered as part of the formal economy.

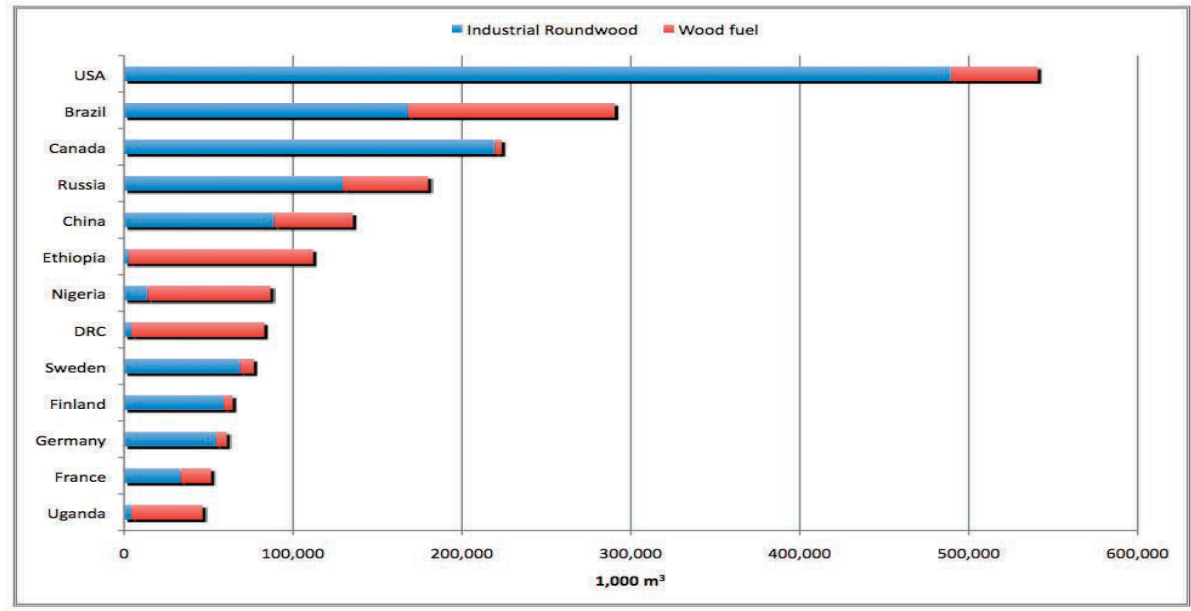

Figure 2: Highest wood fuel and industrial roundwood producing countries (Source of data: FAO 2006a)

As the next section notes, many important economic contributions of forests are inadequately measured. Subsistence use of forests and informal trading of forest products are very likely to go unrecorded: partly because customary owners have no wish to be noticed by government bodies or to have their use rights contested and partly - as a result - because these uses are not consequently quantified as part of regulation or taxation.

\section{Monetized and cash value contributions from forests}

Given the above challenges, what can we say about the contribution of forests at the global and regional scales in shaping and impacting economic life? Research by Lebedys (2008), which reviews and summarized data provided by countries themselves, provides important answers. First, figure 3 below indicates that taken together, 13 million people are reported as of 2006 to be employed in the "formal" sector either through forest management or value added manufacturing within wood processing or pulp and paper production.

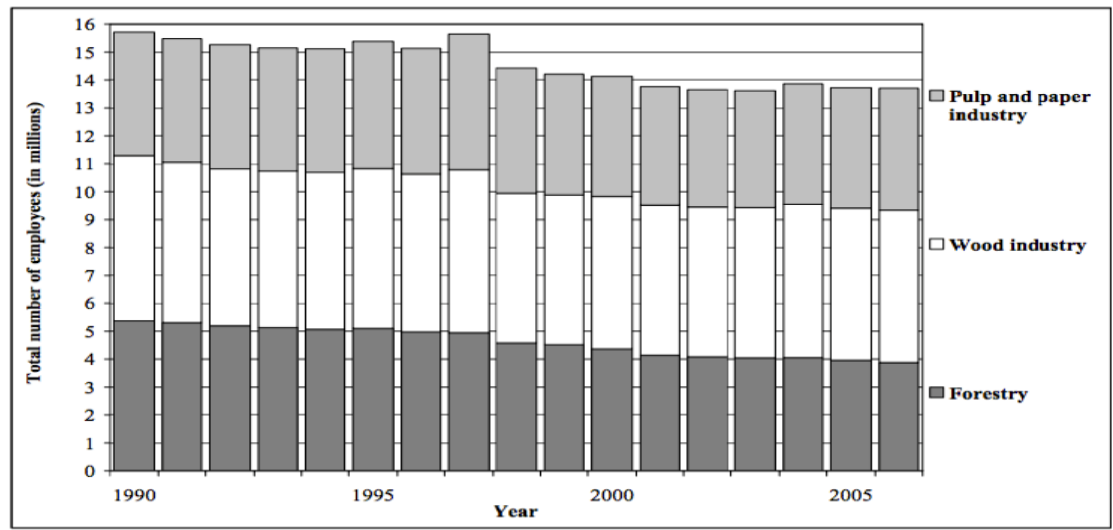

Figure 3: Forest sector formal employment by industry type

(Source: FAO 2011) 
We also know that these aggregate figures reveal a decline from 15.75 million employed in 1999, and they mask the fact that this is almost exclusively owing to declines in forestry employment itself, with pulp and paper and wood industry remaining fairly constant. What explains these declines? One answer may be owing to increased efficiencies in mechanization. The other may be owing to the increase in employment in other agricultural crops, notably palm oil, which has been replacing both pulp and paper plantations as well as contributing to conversion of natural forests. Hence, there is no doubt that if we included palm oil production in these trends we would see a significant increase in employment. To be sure, the role of palm oil in encouraging land use conversion, shaping land tenure and community participation, and, in contributing to climate emissions, all render decisions about whether to measure palm oil plantations and their different effects highly contentious. The point is simply to note these dynamics and that they affect and shape whether when and how employment of people in resource extraction occurs and is counted.

Second, we know that the relative importance of forest sector employment, value added, and exports vary significantly across regions. For instance, in the Asia - Pacific Developing Region 5.3 million people are formally employed in forestry or 39 percent of the world's total forest sector work force. This is important, since it is clear that forests play a greater role in developing countries than it does in developed ones, with profound policy implications for the development of forest management choices which help contribute to poverty alleviation. At the same time formal employment in Sub-Saharan Africa is only 500,000 or 3 percent of the world's total, while employment in North America, Western Europe, and Eastern Europe is 1.4, 1.7 and 2.1 percent respectively.

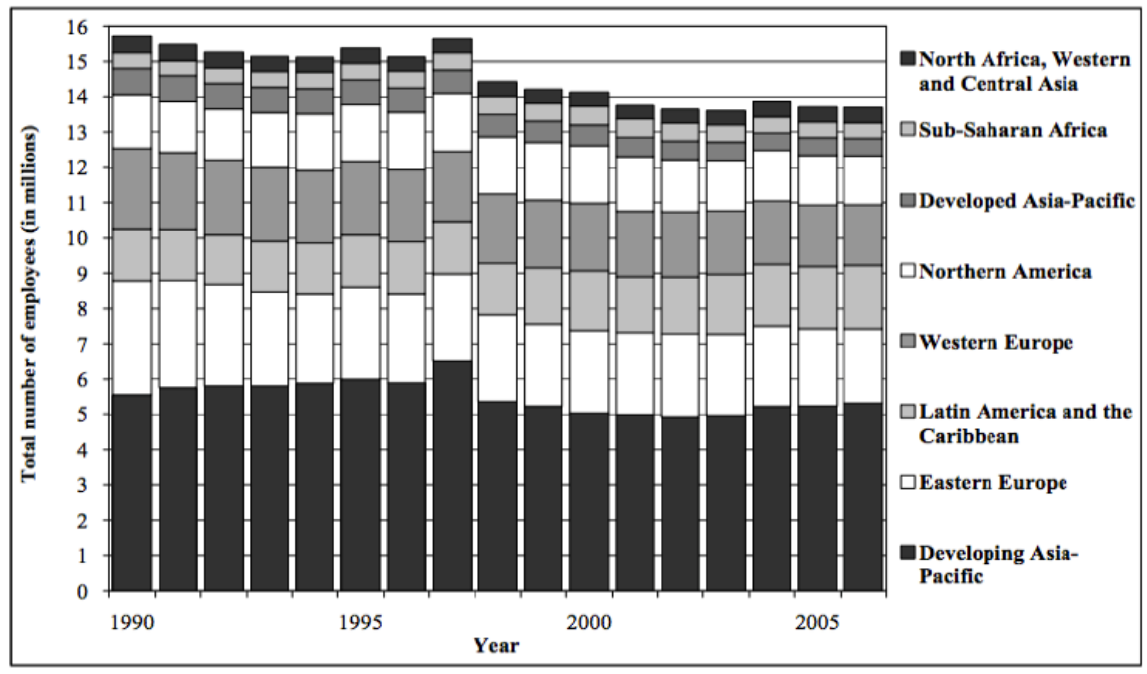

(Source: FAO 2011)

Figure 4: Forest sector formal employment by region

Third, the relatively high degree of formal employment in developing Asia-Pacific Rim countries does not translate into higher forest exports, which stand at $14 \%$ of global totals, in contrasts to Western and Eastern Europe's combined total of $56 \%$. Likewise while Asia-Pacific Rim developing countries account for $17 \%$ ( $\$ 78$ billion) of the world's value added, North America, which a fraction of the formally employed work force, contributes $30 \%$ (140 billion) of the value added.

Important trends also emerge when comparing forest sector employment and value added to other sectors. In these cases, developing Asia-Pacific Rim countries, owing to high population levels, sees its share of labor force relatively low at 0.6 percent, which, owing to increasing population growth and declines in forest management employment, has shrunk from $1 \%$ in 1990 and .6 in 2006. Reflecting low employment numbers and the importance of the informal economy, both the Sub-Saharan Africa region and the North Africa, and Western and Central Asia regions only contribute 0.1 and 0.2 percent respectively to overall employment levels. Meanwhile as a share of labor force, North America claims 0.8 percent, Eastern Europe 1.2 percent and Western Europe about 0.9 percent of overall employment (FAO 2011).

These trends are also reflected in overall contribution to GDP with forestry generally declining compared to other sectors from 1990 to 2006, in part a reflection of government and international efforts to initiate policies aimed at fostering growth and development as a way to alleviate poverty and diversify economic activity. Still, even these direct and formal figures show that forestry remains important to GDP accounting for $0.7 \%$ in 2006 in developing Asia-Pacific Rim countries, 1.3 in developed Asia-Pacific, 1 percent in North America, 0.9 in Western Europe and 1.2 in Eastern Europe. What is interesting is that despite the low share of 
the labor force, the highest contribution in any region to share of GDP is found in sub-Saharan Africa, which accounts for $1.8 \%$ (FAO 2011).

It is also important to note that although employment has been declining, both value added contributions and exports increased in most regions. For instance, in developing Asia-Pacific Countries value added contributions increased from $6.2 \%$ from 2000 to 2006 while exports increased by $6.2 \%$. Likewise in North Africa, Western and Central Asia exports increased $7.4 \%$ and value added 1.6\%.

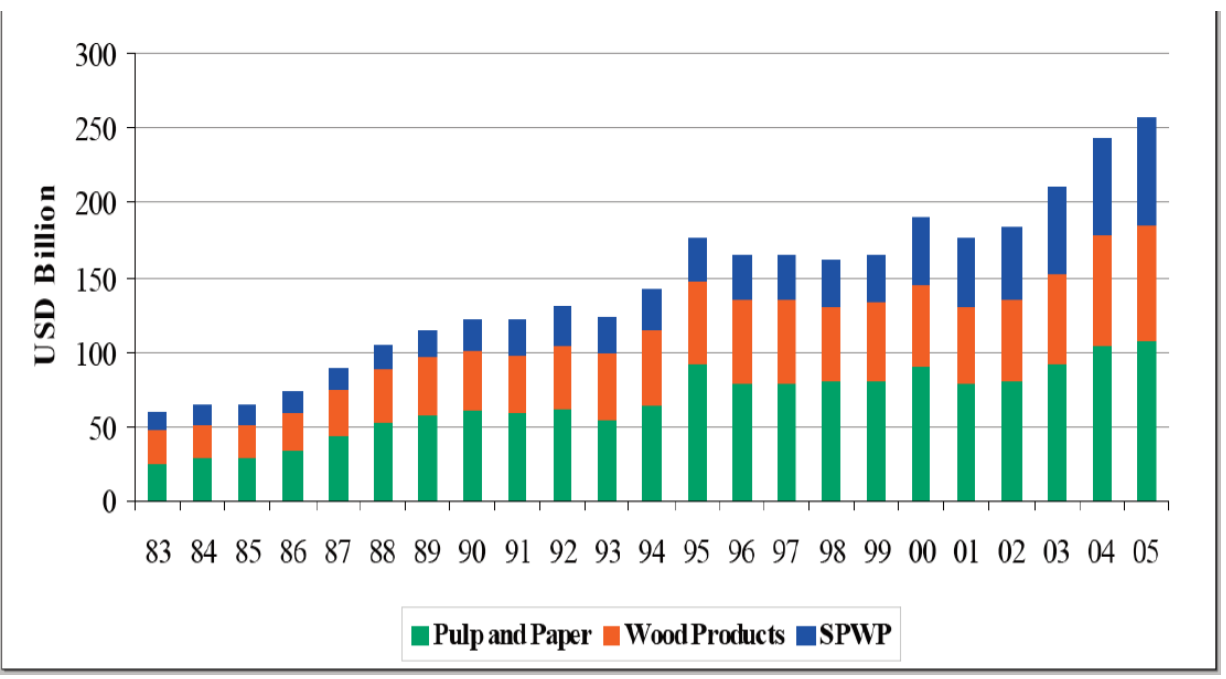

(Source: ACPWP 2007)

Figure 5: Formal exports forest products

Overall, as the figure above from McDermott et al., with data from the FAO Advisory Committee on Paper and Wood Products (ACPWP 2007) reviews, exports in pulp and paper products, wood products, and "secondary processed wood products (SPWP), which are products produced from sawnwood (i.e. furniture, cabinets, doors) have been on an upswing since 1990.

What these single snap-shot figures arguably underestimate is the role of the forest sector in terms of its contributions to economic development. Development economists have long asserted that as countries transition, they pass through different stages that are generally characterized by an emphasis on resource extraction which, following capital investment, mechanization and training of the labor force, gives way to broader diversification and development. We have traced some of these trajectories in the previous section. But the impact of these stages on ecosystem preservation has been hotly disputed, from those asserting that countries eventually come to give increasing value to the environment following the stages implied by the Kuznets' curve, to those that assert that the new "legible" and divided landscape is a far cry from, and can never return to, the pristine state that existed originally. Nonetheless, that these stages do exist, and that forestry plays a key role in them, means that data showing declines in forest sector contributions underestimate the role it played, and arguably continues to play, in fostering increased diversification. In other words, the increased diversification through which forestry plays a key role results in statistics on employment and value added that underestimate its influence.

Finally, we note that forests plays a greater role when we consider their contributions as a percentage of exports than in direct formal employment and GDP, though, this share has also been declining (FAO 2011). In North America forestry exports accounts for 7.1 in 1990 and 3.8 in 2006. The percent of exports was $3.4 \%$ in 1990 in developing Asia-Pacific, which decline in 2006 to 1.4\% while in Sub-Saharan Africa this figure declined from 3.6 to 1.9\%. Regions that saw increases from 1990 to 2006 include North Africa, Western and Central Asia (0.2 to 0.4), and Eastern Europe (3.6 to 3.9), although 2000 in Eastern Europe was actually the highest with 5\%. Interestingly, exports account for 1.7 of GDP among all tropical countries and 1.1 for temperate ones.

Overall, the data reveal clear trends. The forest sector globally and within many regions has been, and continues to be, an important contributor to formal and direct employment. At the same time, these impacts have declined as a share since 1990 as economic diversification continues to take place amidst increasing economic liberalization. The role of forest products and trade has also been increasing. These changing dynamics underscore the importance of maintaining and developing "real time" data sets with which to map these changes, and the numerous ways in which the forest sector contributes historically to economic life, and the expanding and changing ways in which it continues to play a key role within the global political economic and economic development. 


\section{References}

[1]. Arce-Nazario, J. A. (2007). "Human landscapes have complex trajectories: reconstructing Peruvian Amazon landscape history from 1948 to 2005." Landscape Ecology 22: 89-101.

[2]. Barton, G. (2001). "Empire forestry and the origins of environmentalism." Journal of Historical Geography 27(4): 529-552.

[3]. Chomitz, K. and Kumari, K. (1998). The Domestic Benefits of Tropical Forests: A Review. The World Bank Research Observer 13(1): 13-35.

[4]. $\quad$ FAO (2006). "Forests and Human Health." Unasylva 57(2): Special Issue.

[5]. FAO (2006). State of the World's Forests 2006. Rome, FAO

[6]. FAO (2007). State of the World's Forests 2007. Rome, FAO

[7]. FAO (2008). State of the World's Forests 2008. Rome, FAO

[8]. FAO (2009). State of the World's Forests 2009. Rome, FAO

[9]. FAO (2010). Criteria and indicators for sustainable woodfuels. FAO Forestry Paper No. 160. Rome, FAO.

[10]. FAO (2010). State of the World's Forests 2010. Rome, FAO

[11]. FAO (2011). State of the World's Forests 2011. Rome, FAO

[12]. FAO (2012). State of the World's Forests 2012. Rome, FAO

[13]. Ferraro, P. J., Lawlor, K., Mullan, K., and Pattanayak, S. (2012). "Forest Figures: Ecosystem Services Valuation and Policy Evaluation in Developing Countries." Review of Environmental Economics and Policy 6(1): 20-44.

[14]. Grainger, A. (1995). "The forest transition: an alternative approach." Area: 242-251.

[15]. Guha, R (2000) The Unquiet Woods: Ecological Change and Peasant Resistance in the Himalaya

[16]. Lebedys, A. (2008). Contribution of the Forestry Sector to National Economies, 1990-2006. FAO, Rome.

[17]. Nagendra, H. (2010). "Reforestation and regrowth in the human dominated landscapes of South Asia." Reforesting Landscapes: 149-174.

[18]. Perz, S. G. and S. D.L. (2003). "Secondary forest expansion in the Brazilian Amazon and the refinement of forest transition theory." Society and Natural Resources 16: 277-294.

[19]. Richards, J. F. and R. P. Tucker (1988). World deforestation in the twentieth century. Durham: Duke University Press.

[20]. Song, C. and Y. Zhang (2010). "Forest cover in China from 1949 to 2006." Reforesting Landscapes: 341-356.

[21]. Vedeld, P., Angelsen, A., Bojo, J., Sjaastad, E., and Berg, G. (2007). "Forest environmental incomes and the rural poor." Forest Policy and Economics 9(7): 869-879.

[22]. Williams, M. (2002). Deforesting the Earth: From Prehistory to Global Crisis. University of Chicago Press. 